\title{
Unsteady Magnetohydrodynamic Boundary Layer Flow near the Stagnation Point towards a Shrinking Surface
}

\author{
Santosh Chaudhary, Pradeep Kumar \\ Department of Mathematics, Malaviya National Institute of Technology, Jaipur, India \\ Email: d11.santosh@yahoo.com, pradeep17matrix@gmail.com
}

Received 23 June 2015; accepted 27 July 2015; published 30 July 2015

Copyright @ 2015 by authors and Scientific Research Publishing Inc.

This work is licensed under the Creative Commons Attribution International License (CC BY). http://creativecommons.org/licenses/by/4.0/

cC) (7) Open Access

\begin{abstract}
The unsteady two-dimensional, laminar flow of a viscous, incompressible, electrically conducting fluid towards a shrinking surface in the presence of a uniform transverse magnetic field is studied. Taking suitable similarity variables, the governing boundary layer equations are transformed to ordinary differential equations and solved numerically by a perturbation technique for a small magnetic parameter. The effects of various parameters such as unsteadiness parameter, velocity parameter, magnetic parameter, Prandtl number and Eckert number for velocity and temperature distributions along with local Skin friction coefficient and local Nusselt number have been discussed in detail through numerical and graphical representations.
\end{abstract}

Keywords

Unsteady Flow, Magnetohydrodynamic, Boundary Layer, Stagnation Point, Shrinking Surface

\section{Introduction}

Stagnation flow of an incompressible viscous fluid over a shrinking sheet has many important practical applications in engineering and industrial processes, such as the extrusion of a polymer in a melt-spinning process, continuous casting of metals, the aerodynamic extrusion of plastic sheets, the cooling of metallic sheets or electronic chips and many others. In all these cases, a study of fluid flow and heat transfer has important significance because the quality of the final product depends on the rate of cooling and the process of stretching.

In recent years, the boundary layer flow due to a shrinking sheet has attraction of many researchers because of its useful applications. A very interesting example in which the shrinking sheet situation occurs is of a rising shrinking balloon. Shrinking film is also a common application of shrinking sheet problems in engineering and 
industries. Shrinking film is very useful in packaging of bulk products because it can be unwrapped easily with adequate heat.

From the stretching case, the flow of shrinking sheet is different and the fluid is attracted towards a slot. Physically, the generated velocity at shrinking sheet has an unsteady flow due to the application of inadequate suction and is not confined within the boundary layer.

In view of all these applications, Sakiadis [1] initiated the study of boundary layer flow over a continuous solid surface moving with constant speed. Later Crane [2] considered the problem of the flow over a linearly stretching sheet in an ambient fluid and gave a similarity solution in closed analytical form for the steady two-dimensional problem. Gupta and Gupta [3], and Vleggaar [4] have investigated the solution of stretching flow problems at the constant surface temperature while Soundalgekar and Ramana [5] and Grubka and Bobba [6] have analysed the solution of stretching flow problems with a variable surface temperature. Many researchers such as Magyari and Keller [7], Elbashbeshy and Bazid [8], Jat and Chaudhary [9]-[11], Bachok et al. [12] and Zheng et al. [13] have analyzed the stretching sheet problems with different aspects of fluid, such as the heat transfer, the permeability of the surface and the unsteadiness flow. Mahapatra and Nandy [14] [15] studied the unsteady stagnation-point flow and heat transfer over an unsteady shrinking sheet. Recently Aly and Vajravelu [16] and Chaudhary and Kumar [17] discussed numerical solutions of boundary layer flow problems over different surfaces in a porous medium. More recently Nandy et al. [18] and Rosca and Pop [19] investigated the unsteady boundary layer flow over a permeable stretching or shrinking surface.

Realizing the increasing technical applications of the magnetohydrodynamic effects, the aim of the present work is concerned with a steady, two-dimensional unsteady stagnation flow of an electrically conducting fluid over a shrinking surface in the presence of a uniform transverse magnetic field.

\section{Formulation of the Problem}

Consider an unsteady two-dimensional steady flow $(u, v, 0)$ of a viscous incompressible electrically conducting fluid near a stagnation point over a continuously shrinking surface placed in the plane $y=0$ of a Cartesian coordinate system in the presence of time dependent free stream. The $x$-axis is taken along the shrinking surface in the direction of motion and $y$-axis is perpendicular to it. A uniform magnetic field of constant strength $\left(0, H_{0}, 0\right)$ is assumed to be applied normal to the shrinking surface (Figure 1 ). The surface is assumed to be

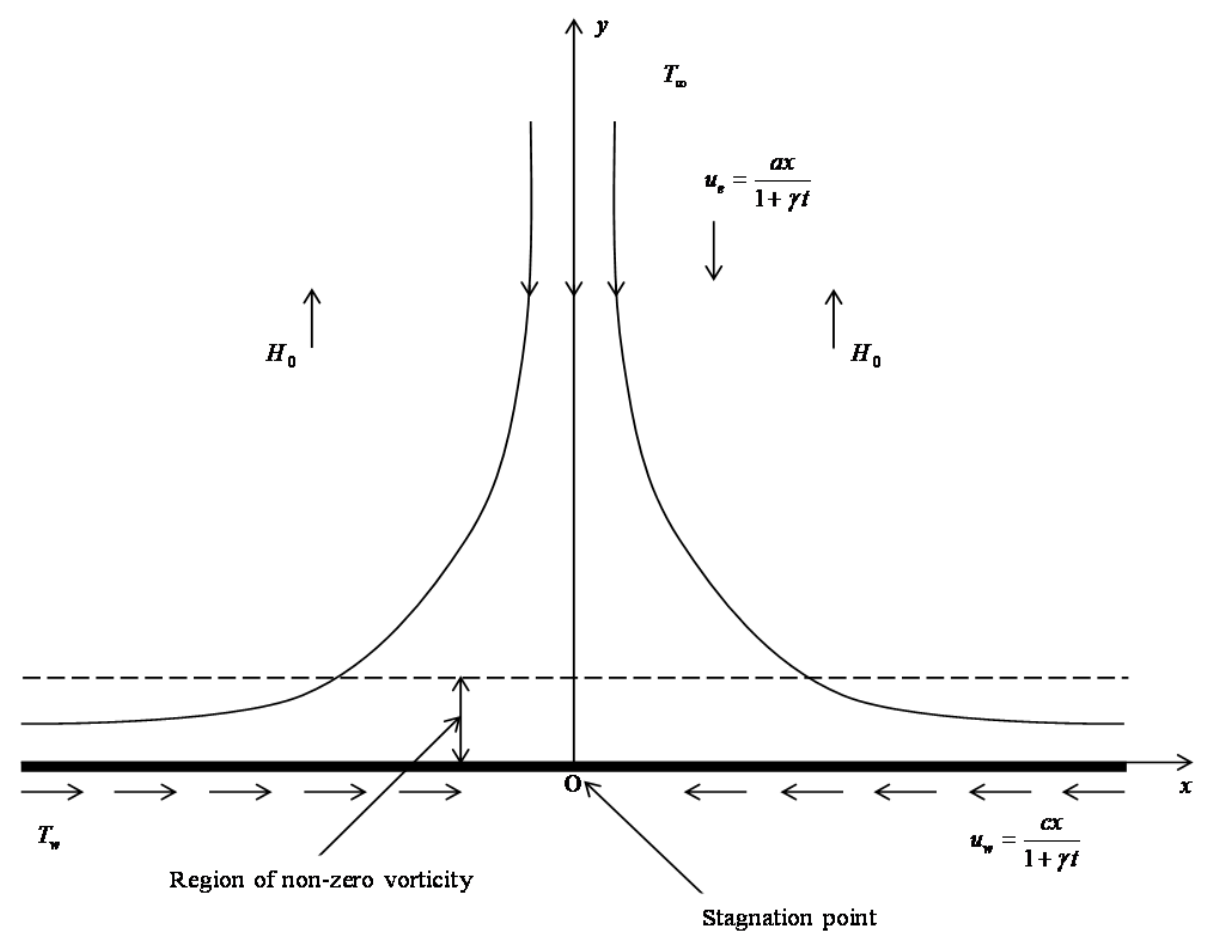

Figure 1. Coordinate system for the shrinking surface. 
highly elastic and is shrinking in the $x$-direction with a velocity is $u_{w}$ and surface temperature $T_{w}$ while the velocity of the flow, external to the boundary layer is $u_{e}$ and temperature $T_{\infty}$. Therefore, under the usual boundary layer and Boussinesq approximations, the systems of boundary layer equations are given by

$$
\begin{gathered}
\frac{\partial u}{\partial x}+\frac{\partial v}{\partial y}=0 \\
\frac{\partial u}{\partial t}+u \frac{\partial u}{\partial x}+v \frac{\partial u}{\partial y}=\frac{\partial u_{e}}{\partial t}+u_{e} \frac{\partial u_{e}}{\partial x}+v \frac{\partial^{2} u}{\partial y^{2}}-\frac{\sigma_{e} \mu_{e}^{2} H_{0}^{2} u}{\rho} \\
\frac{\partial T}{\partial t}+u \frac{\partial T}{\partial x}+v \frac{\partial T}{\partial y}=\frac{v}{\operatorname{Pr}} \frac{\partial^{2} T}{\partial y^{2}}+\frac{\mu}{\rho C_{p}}\left(\frac{\partial u}{\partial y}\right)^{2}+\frac{\sigma_{e} \mu_{e}^{2} H_{0}^{2} u^{2}}{\rho C_{p}}
\end{gathered}
$$

where $v$ is the coefficient of kinematic viscosity, $\sigma_{e}$ the electrical conductivity, $\mu_{e}$ the magnetic permeability, $\rho$ the density, Pr the Prandtl number $\left(=\frac{\mu C_{p}}{\kappa}\right), \mu$ the coefficient of viscosity, $C_{p}$ the specific heat at constant pressure and $\kappa$ the thermal conductivity. The other symbols have their usual meanings.

The boundary conditions are

$$
\begin{aligned}
& y=0: \quad u=u_{w}=\frac{c x}{1+\gamma t}, v=0 ; T=T_{w} \\
& y=\infty: u=u_{e}=\frac{a x}{1+\gamma t} ; T=T_{\infty}
\end{aligned}
$$

where $c$ is a constant, $\gamma$ is the shrinking rate and $a$ is the strength of the stagnation point flow.

\section{Analysis}

The continuity Equation (1) is identically satisfied by stream function $\psi(x, y, t)$, defined as

$$
u=\frac{\partial \psi}{\partial y}, v=-\frac{\partial \psi}{\partial x}
$$

For the solution of the momentum and the energy Equations (2) and (3), the following dimensionless variables are defined:

$$
\begin{gathered}
\psi(x, y, t)=\sqrt{\frac{a v}{1+\gamma t}} x f(\eta) \\
\eta=\sqrt{\frac{a}{v(1+\gamma t)}} y \\
\theta(\eta)=\frac{T-T_{\infty}}{T_{w}-T_{\infty}}
\end{gathered}
$$

Equations (5) to (8), transform Equations (2) and (3) into

$$
\begin{gathered}
f^{\prime \prime \prime}+\left(f+\frac{1}{2} \eta \beta\right) f^{\prime \prime}+\left(\beta-\alpha \operatorname{Re}_{m}^{2}-f^{\prime}\right) f^{\prime}+1-\beta=0 \\
\theta^{\prime \prime}+\operatorname{Pr}\left(f+\frac{1}{2} \eta \beta\right) \theta^{\prime}+\frac{1}{\alpha^{2}} \operatorname{Pr} E c f^{\prime \prime 2}+\frac{1}{\alpha} \operatorname{Pr} E c \operatorname{Re}_{m}^{2} f^{\prime 2}=0
\end{gathered}
$$

where a prime (') denotes differentiation with respect to $\eta, \beta=\frac{\gamma}{a}$ is the unsteadiness parameter, $\alpha=\frac{c}{a}$ is 
the velocity parameter, $\operatorname{Re}_{m}=\mu_{e} H_{0} \sqrt{\frac{\sigma_{e} X}{\rho u_{w}}}$ is the Magnetic parameter and $E c=\frac{u_{w}^{2}}{C_{p}\left(T_{w}-T_{\infty}\right)}$ is the Eckert number.

The corresponding boundary conditions are

$$
\begin{aligned}
& \eta=0: \quad f=0, f^{\prime}=\alpha ; \theta=1 \\
& \eta=\infty: \quad f^{\prime}=1 ; \theta=0
\end{aligned}
$$

For numerical solution of the Equations (9) and (10), through a perturbation technique, by assuming the following power series in a small magnetic parameter $\mathrm{Re}_{m}^{2}$ as

$$
\begin{aligned}
& f(\eta)=\sum_{i=0}^{\infty}\left(\operatorname{Re}_{m}^{2}\right)^{i} f_{i}(\eta) \\
& \theta(\eta)=\sum_{j=0}^{\infty}\left(\operatorname{Re}_{m}^{2}\right)^{j} \theta_{j}(\eta)
\end{aligned}
$$

Substituting Equations (12) and (13) and its derivatives in Equations (9) and (10) and then equating the coefficients of like powers of $\mathrm{Re}_{m}^{2}$, we get the following set of equations

$$
\begin{gathered}
f_{0}^{\prime \prime \prime}+\left(f_{0}+\frac{1}{2} \eta \beta\right) f_{0}^{\prime \prime}+\left(\beta-f_{0}^{\prime}\right) f_{0}^{\prime}=\beta-1 \\
\theta_{0}^{\prime \prime}+\operatorname{Pr}\left(f_{0}+\frac{1}{2} \eta \beta\right) \theta_{0}^{\prime}=-\frac{1}{\alpha^{2}} \operatorname{Pr} E c f_{0}^{\prime \prime 2} \\
f_{1}^{\prime \prime \prime}+\left(f_{0}+\frac{1}{2} \eta \beta\right) f_{1}^{\prime \prime}+\left(\beta-2 f_{0}^{\prime}\right) f_{1}^{\prime}+f_{0}^{\prime \prime} f_{1}=\alpha f_{0}^{\prime} \\
\theta_{1}^{\prime \prime}+\operatorname{Pr}\left(f_{0}+\frac{1}{2} \eta \beta\right) \theta_{1}^{\prime}=-\operatorname{Pr} f_{1} \theta_{0}^{\prime}-\frac{1}{\alpha^{2}} \operatorname{Pr} E c\left(2 f_{0}^{\prime \prime} f_{1}^{\prime \prime}+\alpha f_{0}^{\prime 2}\right) \\
f_{2}^{\prime \prime \prime}+\left(f_{0}+\frac{1}{2} \eta \beta\right) f_{2}^{\prime \prime}+\left(\beta-2 f_{0}^{\prime}\right) f_{2}^{\prime}+f_{0}^{\prime \prime} f_{2}=-f_{1} f_{1}^{\prime \prime}+\left(f_{1}^{\prime}+\alpha\right) f_{1}^{\prime} \\
\theta_{2}^{\prime \prime}+\operatorname{Pr}\left(f_{0}+\frac{1}{2} \eta \beta\right) \theta_{2}^{\prime}=-\operatorname{Pr}\left(f_{1} \theta_{1}^{\prime}+f_{2} \theta_{0}^{\prime}\right)-\frac{1}{\alpha^{2}} \operatorname{Pr} E c\left(2 f_{0}^{\prime \prime} f_{2}^{\prime \prime}+f_{1}^{\prime \prime 2}+2 \alpha f_{0}^{\prime} f_{1}^{\prime}\right)
\end{gathered}
$$

with the boundary conditions

$$
\begin{aligned}
& \eta=0: \quad f_{i}=0, f_{0}{ }^{\prime}=\alpha, f_{j}^{\prime}=0 ; \theta_{0}=1, \theta_{j}=0 \\
& \eta=\infty: \quad f_{0}^{\prime}=1, f_{j}^{\prime}=0 ; \theta_{i}=0 \\
& i \geq 0, j>0
\end{aligned}
$$

The Equation (14) is obtained by Mahapatra and Nandy [14] for the non-magnetic case and the remaining equations are ordinary linear differential equations and have been solved numerically by Runge-Kutta method of fourth order. The velocity and temperature distributions for various values of parameters are shown in Figure 2 to Figure 6 respectively.

\section{Skin Friction and Surface Heat Transfer}

The physical quantities of interest, the local skin friction coefficient $C_{f}$ and the local Nusselt number $N u$ i.e. surface heat transfer are given by:

$$
C_{f}=\frac{\tau_{w}}{\rho u_{w}^{2} / 2}=\frac{\mu\left(\frac{\partial u}{\partial y}\right)_{y=0}}{\rho u_{w}^{2} / 2}
$$




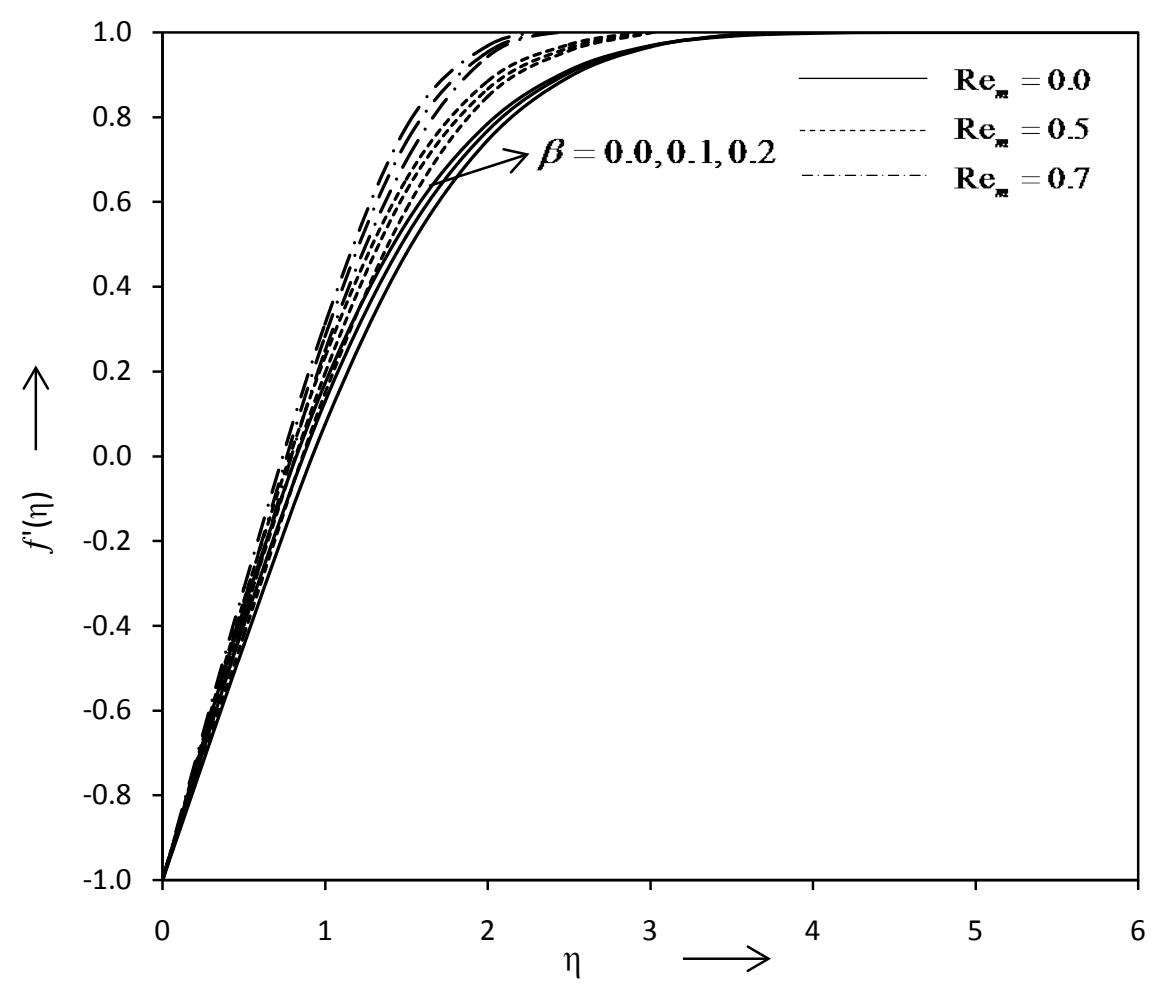

Figure 2. Velocity distribution against $\eta$ for various values of $\beta$ and $\operatorname{Re}_{m}$ with $\alpha=-0.1$.

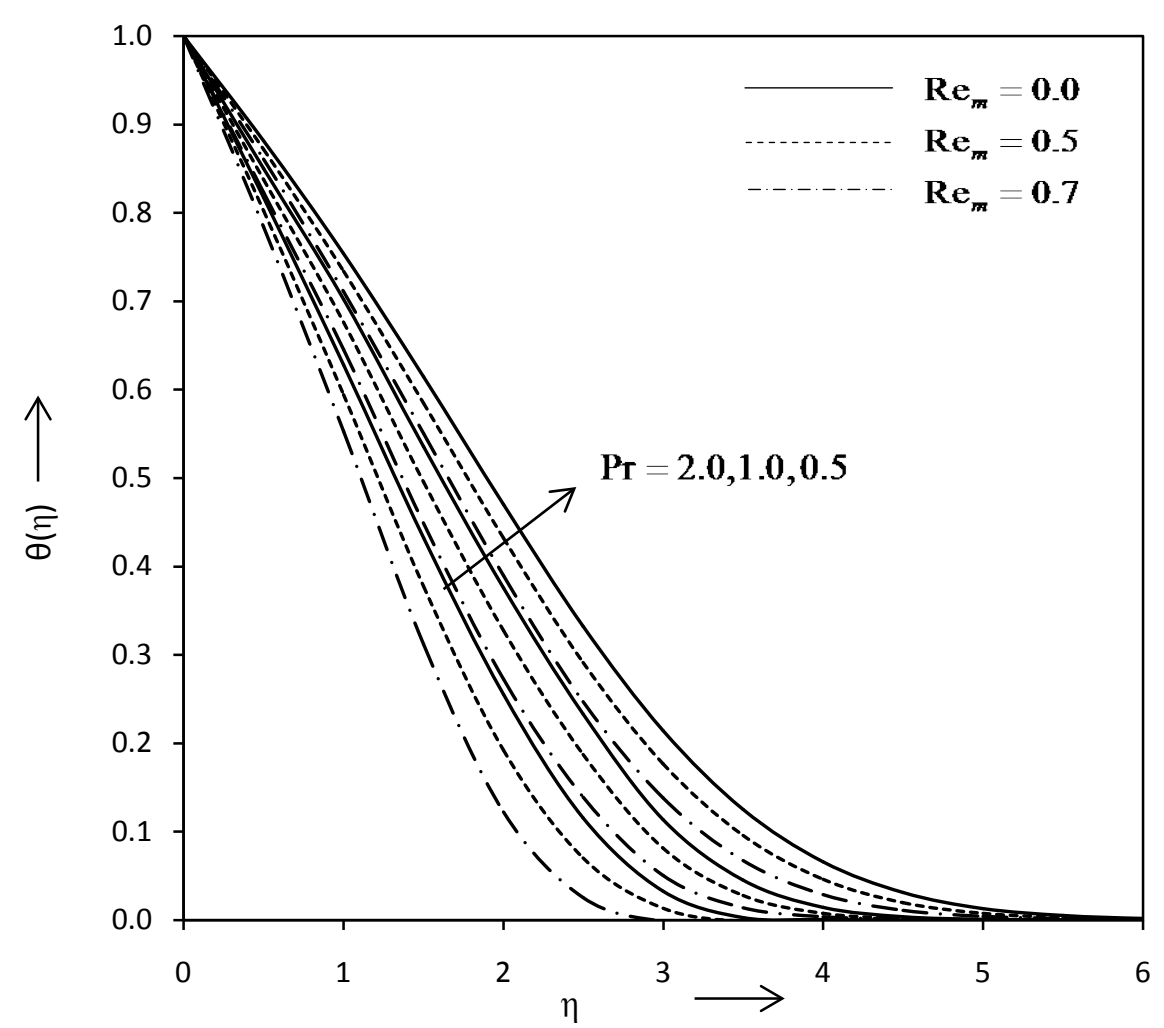

Figure 3. Temperature distribution against $\eta$ for various values of $\operatorname{Re}_{m}$ and $\operatorname{Pr}$ with $\beta=0.1, \alpha=-1.0$ and $E c=0.000$. 


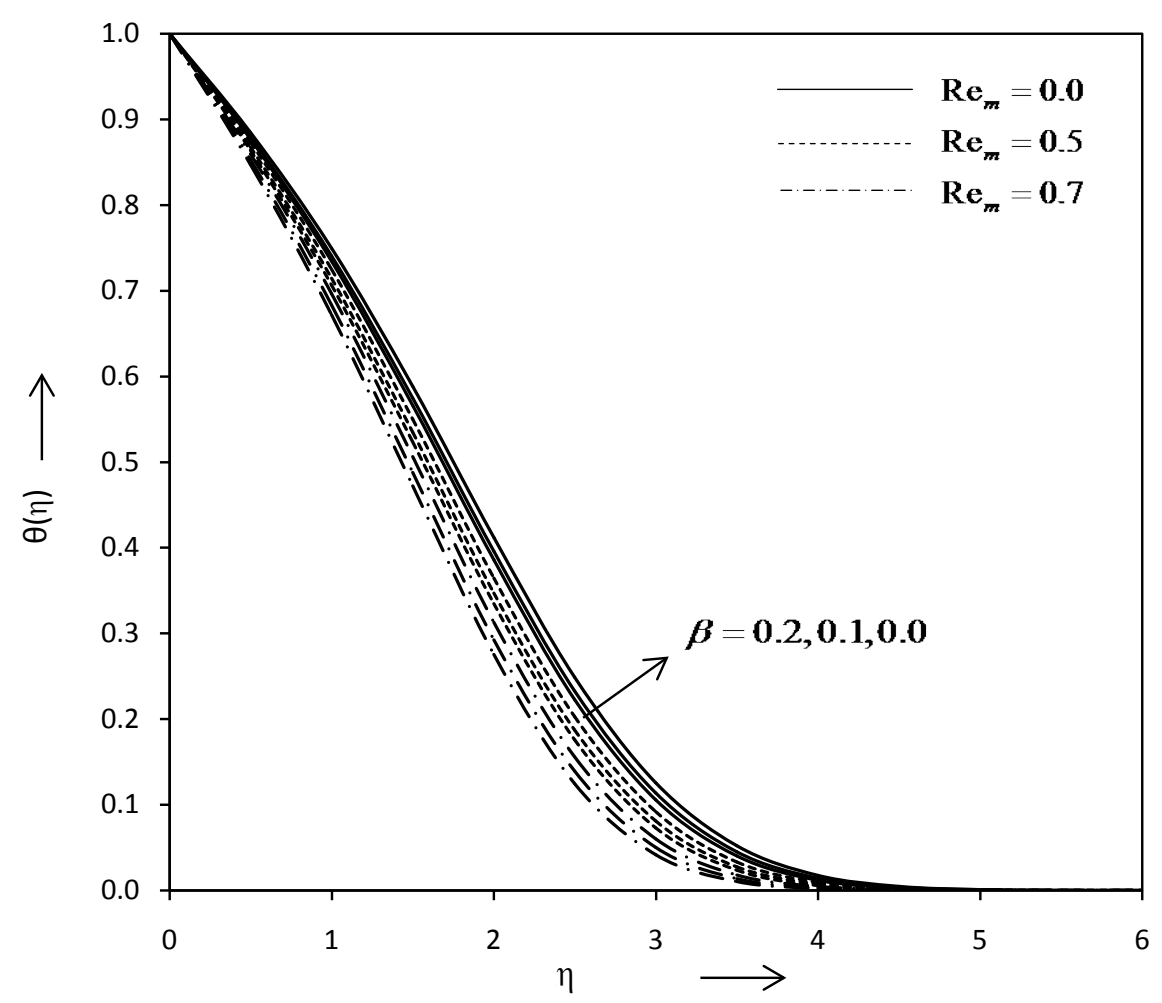

Figure 4. Temperature distribution against $\eta$ for various values of $\beta$ and $\operatorname{Re}_{m}$ with $\alpha=-1.0, \operatorname{Pr}=1.0$ and $E c=0.000$.

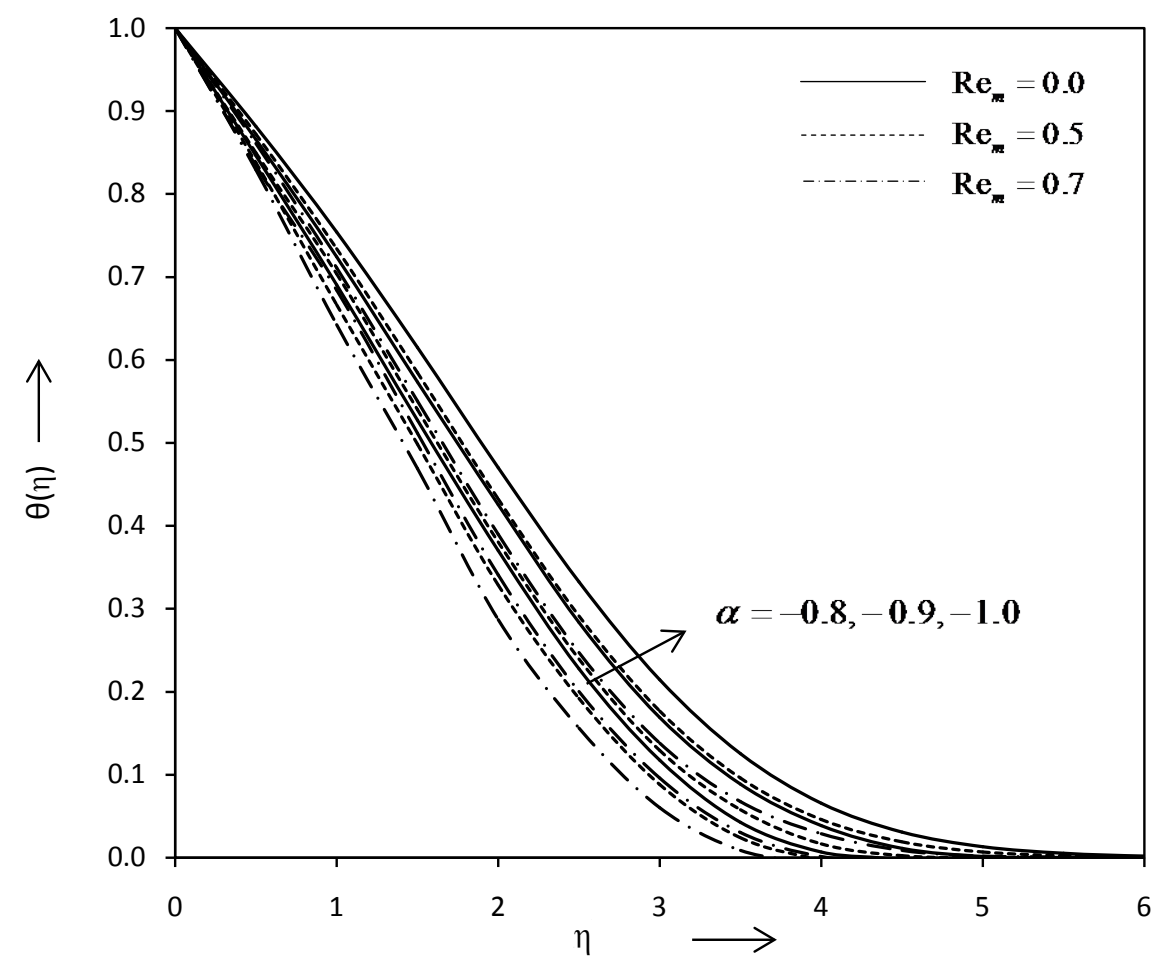

Figure 5. Temperature distribution against $\eta$ for various values of $\alpha$ and $\operatorname{Re}_{m}$ with $\beta=0.1, \operatorname{Pr}=0.5$ and $E c=0.000$. 


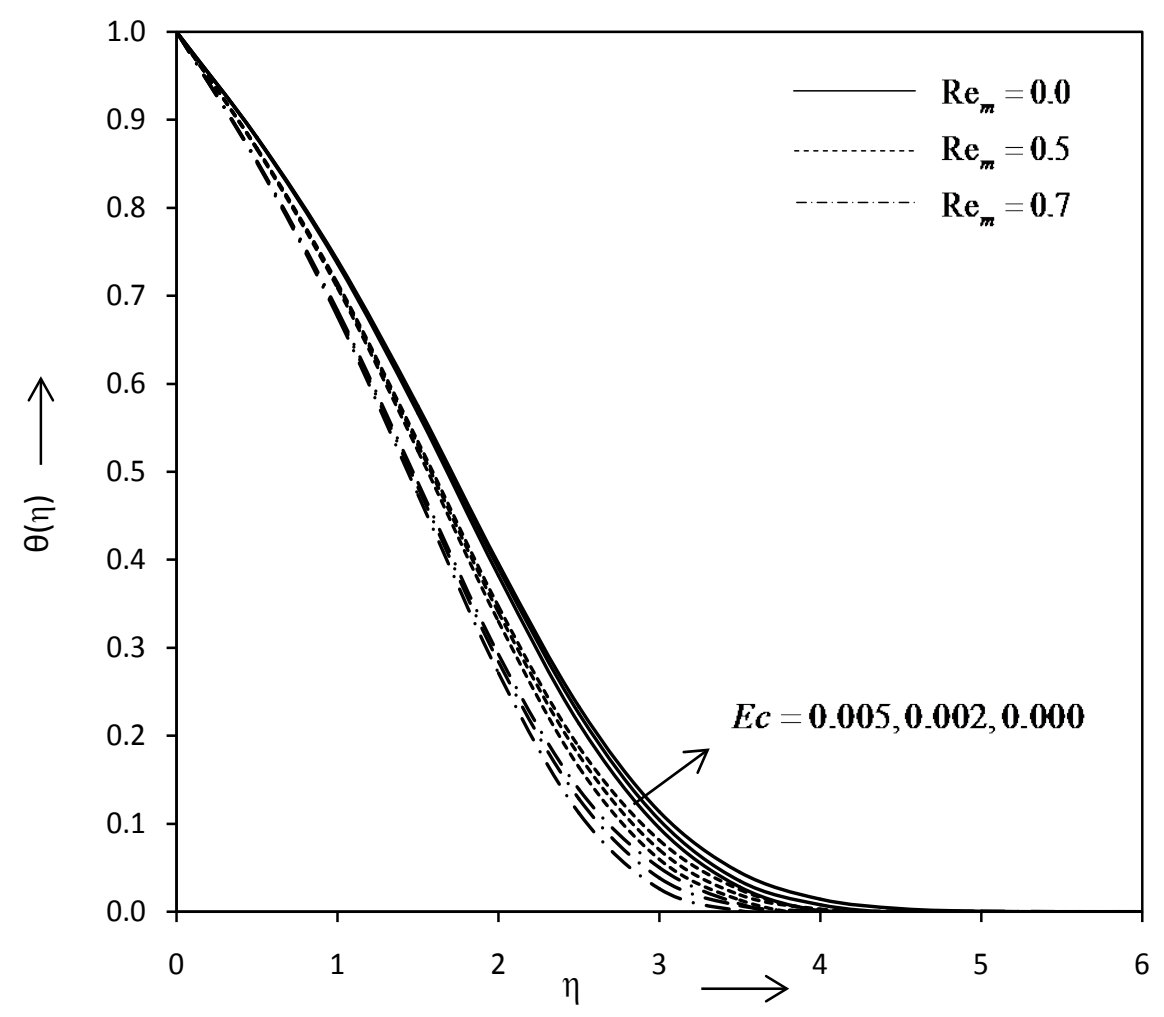

Figure 6. Temperature distribution against $\eta$ for various values of $\operatorname{Re}_{m}$ and $E c$ with $\beta=0.1, \alpha=-1.0$ and $\operatorname{Pr}=1.0$.

and

$$
N u=-\frac{x\left(\frac{\partial T}{\partial y}\right)_{y=0}}{\left(T_{w}-T_{\infty}\right)}
$$

which, in the present case can be expressed in the following forms

$$
\begin{aligned}
C_{f} & =\frac{2}{\alpha^{3 / 2} \sqrt{\mathrm{Re}}} f^{\prime \prime}(0) \\
& =\frac{2}{\alpha^{3 / 2} \sqrt{\operatorname{Re}}} \sum_{i=0}^{\infty}\left(\operatorname{Re}_{m}^{2}\right)^{i} f_{i}^{\prime \prime}(0)
\end{aligned}
$$

and

$$
\begin{aligned}
N u & =-\sqrt{\frac{\operatorname{Re}}{\alpha}} \theta^{\prime}(0) \\
& =-\sqrt{\frac{\operatorname{Re}}{\alpha}} \sum_{j=0}^{\infty}\left(\operatorname{Re}_{m}^{2}\right)^{j} \theta_{j}^{\prime}(0)
\end{aligned}
$$

where $\operatorname{Re}=\frac{u_{w} x}{v}$ is the local Reynolds number.

Numerical values of the functions $f^{\prime \prime}(0)$ and $\theta^{\prime}(0)$, which are proportional to local skin friction and local heat transfer rate at the surface respectively for various values of the parameter are presented in Table 1 and Table 2. 
Table 1. Numerical values of $f^{\prime \prime}(0)$ for various values of the parameters $\beta, \alpha \& \operatorname{Re}_{m}$.

\begin{tabular}{|c|c|c|c|c|c|c|c|c|c|}
\hline \multirow{3}{*}{$\alpha$} & \multicolumn{9}{|c|}{$f^{\prime \prime}(0)$} \\
\hline & \multicolumn{3}{|c|}{$\beta=0.0$} & \multicolumn{3}{|c|}{$\beta=0.1$} & \multicolumn{3}{|c|}{$\beta=0.2$} \\
\hline & $\operatorname{Re}_{m}=0.0$ & $\operatorname{Re}_{m}=0.5$ & $\mathrm{Re}_{m}=0.7$ & $\operatorname{Re}_{m}=0.0$ & $\operatorname{Re}_{m}=0.5$ & $\operatorname{Re}_{m}=0.7$ & $\operatorname{Re}_{m}=0.0$ & $\mathrm{Re}_{m}=0.5$ & $\mathrm{Re}_{m}=0.7$ \\
\hline-0.1 & 1.3288 & 1.3164 & 1.3104 & 1.2041 & 1.1955 & 1.1937 & 1.0623 & 1.0586 & 1.0512 \\
\hline-0.8 & 1.2614 & 1.2406 & 1.2251 & 1.1985 & 1.1805 & 1.1801 & 1.0210 & 1.0190 & 1.0070 \\
\hline-0.9 & 1.2516 & 1.2303 & 1.2207 & 1.1803 & 1.1795 & 1.1780 & 1.0108 & 1.0099 & 1.0047 \\
\hline-1.0 & 1.2305 & 1.2285 & 1.2178 & 1.1776 & 1.1706 & 1.1701 & 1.0098 & 1.0058 & 1.0015 \\
\hline
\end{tabular}

Table 2. Numerical values of $-\theta^{\prime}(0)$ for various values of the parameters $\beta, \alpha, \operatorname{Re}_{m}, \operatorname{Pr} \& E c$.

\begin{tabular}{|c|c|c|c|c|c|c|c|c|c|c|}
\hline \multirow{4}{*}{$\alpha$} & \multirow{4}{*}{$\operatorname{Pr}$} & \multicolumn{9}{|c|}{$-\theta^{\prime}(0)$} \\
\hline & & \multicolumn{9}{|c|}{$\beta=0.0$} \\
\hline & & \multicolumn{3}{|c|}{$E c=0.000$} & \multicolumn{3}{|c|}{$E c=0.002$} & \multicolumn{3}{|c|}{$E c=0.005$} \\
\hline & & $\operatorname{Re}_{m}=0.0$ & $\mathrm{Re}_{m}=0.5$ & $\operatorname{Re}_{m}=0.7$ & $\operatorname{Re}_{m}=0.0$ & $\operatorname{Re}_{m}=0.5$ & $\mathrm{Re}_{m}=0.7$ & $\mathrm{Re}_{m}=0.0$ & $\mathrm{Re}_{m}=0.5$ & $\mathrm{Re}_{m}=0.7$ \\
\hline \multirow{4}{*}{-1.0} & 0.05 & 0.1493 & 0.1530 & 0.1590 & 0.1493 & 0.1533 & 0.1595 & 0.1493 & 0.1549 & 0.1610 \\
\hline & 0.50 & 0.2259 & 0.2440 & 0.2646 & 0.2259 & 0.2443 & 0.2653 & 0.2259 & 0.2448 & 0.2663 \\
\hline & 1.00 & 0.2227 & 0.2450 & 0.2710 & 0.2227 & 0.2455 & 0.2720 & 0.2227 & 0.2462 & 0.2736 \\
\hline & 2.00 & 0.1815 & 0.2016 & 0.2203 & 0.1815 & 0.2106 & 0.2227 & 0.1815 & 0.2157 & 0.2270 \\
\hline-0.9 & 0.50 & 0.2571 & 0.2705 & 0.2937 & 0.2571 & 0.2712 & 0.2948 & 0.2571 & 0.2719 & 0.2805 \\
\hline-0.8 & 0.50 & 0.2813 & 0.2993 & 0.3017 & 0.2813 & 0.2999 & 0.3024 & 0.2813 & 0.3011 & 0.3021 \\
\hline \multirow{3}{*}{$\alpha$} & \multirow{3}{*}{$\operatorname{Pr}$} & \multicolumn{9}{|c|}{$\beta=0.1$} \\
\hline & & \multicolumn{3}{|c|}{$E c=0.000$} & \multicolumn{3}{|c|}{$E c=0.002$} & \multicolumn{3}{|c|}{$E c=0.005$} \\
\hline & & $\mathrm{Re}_{m}=0.0$ & $\operatorname{Re}_{m}=0.5$ & $\mathrm{Re}_{m}=0.7$ & $\operatorname{Re}_{m}=0.0$ & $\operatorname{Re}_{m}=0.5$ & $\mathrm{Re}_{m}=0.7$ & $\mathrm{Re}_{m}=0.0$ & $\mathrm{Re}_{m}=0.5$ & $\mathrm{Re}_{m}=0.7$ \\
\hline \multirow{4}{*}{-1.0} & 0.05 & 0.1511 & 0.1562 & 0.1620 & 0.1511 & 0.1563 & 0.1622 & 0.1511 & 0.1563 & 0.1623 \\
\hline & 0.50 & 0.2330 & 0.2520 & 0.2741 & 0.2330 & 0.2523 & 0.2748 & 0.2330 & 0.2528 & 0.2758 \\
\hline & 1.00 & 0.2322 & 0.2559 & 0.2842 & 0.2322 & 0.2563 & 0.2852 & 0.2322 & 0.2570 & 0.2866 \\
\hline & 2.00 & 0.1919 & 0.2194 & 0.2536 & 0.1919 & 0.2201 & 0.2553 & 0.1919 & 0.2213 & 0.2578 \\
\hline-0.9 & 0.50 & 0.2661 & 0.2842 & 0.3040 & 0.2661 & 0.2845 & 0.3046 & 0.2661 & 0.2849 & 0.3056 \\
\hline-0.8 & 0.50 & 0.2939 & 0.3102 & 0.3273 & 0.2939 & 0.3105 & 0.3279 & 0.2939 & 0.3109 & 0.3288 \\
\hline \multirow{3}{*}{$\alpha$} & \multirow{3}{*}{$\operatorname{Pr}$} & \multicolumn{9}{|c|}{$\beta=0.2$} \\
\hline & & \multicolumn{3}{|c|}{$E c=0.000$} & \multicolumn{3}{|c|}{$E c=0.002$} & \multicolumn{3}{|c|}{$E c=0.005$} \\
\hline & & $\operatorname{Re}_{m}=0.0$ & $\mathrm{Re}_{m}=0.5$ & $\mathrm{Re}_{m}=0.7$ & $\mathrm{Re}_{m}=0.0$ & $\mathrm{Re}_{m}=0.5$ & $\operatorname{Re}_{m}=0.7$ & $\mathrm{Re}_{m}=0.0$ & $\operatorname{Re}_{m}=0.5$ & $\mathrm{Re}_{m}=0.7$ \\
\hline \multirow{4}{*}{-1.0} & 0.05 & 0.1517 & 0.1576 & 0.1623 & 0.1517 & 0.1585 & 0.1637 & 0.1517 & 0.1595 & 0.1643 \\
\hline & 0.50 & 0.2413 & 0.2623 & 0.2895 & 0.2413 & 0.2653 & 0.2705 & 0.2413 & 0.2693 & 0.2917 \\
\hline & 1.00 & 0.2385 & 0.2639 & 0.2957 & 0.2385 & 0.2644 & 0.2966 & 0.2385 & 0.2650 & 0.2980 \\
\hline & 2.00 & 0.2217 & 0.2415 & 0.2713 & 0.2217 & 0.2503 & 0.2802 & 0.2217 & 0.2505 & 0.2817 \\
\hline-0.9 & 0.50 & 0.2951 & 0.3105 & 0.3317 & 0.2951 & 0.3101 & 0.3320 & 0.2951 & 0.3140 & 0.3303 \\
\hline-0.8 & 0.50 & 0.3216 & 0.3401 & 0.3625 & 0.3216 & 0.3501 & 0.3703 & 0.3216 & 0.3501 & 0.3701 \\
\hline
\end{tabular}




\section{Results and Discussion}

Figure 2 shows the variation of velocity distribution against $\eta$ for various values of the unsteadiness parameter $\beta$, the velocity parameter $\alpha$ and the magnetic parameter $\mathrm{Re}_{m}$. It may be observed that, for the fixed value of the velocity parameter $\alpha$ velocity distribution increases with the decreasing value of the unsteadiness parameter $\beta$, and opposite phenomenon occur for the magnetic parameter $\mathrm{Re}_{m}$, for a fixed $\eta$.

Figure 3 to Figure 6 show the variation of temperature distribution against $\eta$ for the various values of the parameters such as the unsteadiness parameter $\beta$, the velocity parameter $\alpha$, the magnetic parameter $\operatorname{Re}_{m}$, the Prandtl number Pr and the Eckert number Ec. From these figures it may be observed that the temperature distribution decreases with increasing values of the unsteadiness parameter $\beta$, the velocity parameter $\alpha$, the magnetic parameter $\mathrm{Re}_{m}$, the Prandtl number Pr and the Eckert number Ec.

In Table 1, the numerical values of the function $f^{\prime \prime}(0)$ for various values of the unsteadiness parameter $\beta$, the velocity parameter $\alpha$ and the magnetic parameter $\mathrm{Re}_{m}$ are given. It may be observed from the table that the boundary values $f^{\prime \prime}(0)$ for the non-magnetic flow are the same as those obtained by Mahapatra and Nandy [14]. The value of the function $f^{\prime \prime}(0)$ decreases with the increasing values of the unsteadiness parameter $\beta$ and the magnetic parameter $\operatorname{Re}_{m}$ respectively taking other parameters constant and reverse phenomenon occurs for the velocity parameter $\alpha$.

In Table 2, the numerical values of the function $-\theta^{\prime}(0)$ for the different values of the unsteadiness parameter $\beta$, the velocity parameter $\alpha$, the magnetic parameter $\mathrm{Re}_{m}$, the Prandtl number Pr and the Eckert number Ec are given. It may be observed from the table that the boundary values $-\theta^{\prime}(0)$ for the non-magnetic flow are same as those obtained by Mahapatra and Nandy [14]. The value of the function $-\theta^{\prime}(0)$ increases with the increasing value of the unsteadiness parameter $\beta$, considering other parameters constant and same phenomenon occurs for the velocity parameter $\alpha$, the magnetic parameter $\operatorname{Re}_{m}$, the Prandtl number $\operatorname{Pr}<0.5$ and the Eckert number Ec. It is further observed that the function $-\theta^{\prime}(0)$ decreases with an increasing value of the Prandtl number Pr $>0.5$ for fixed other parameters.

\section{Conclusions}

The present work extends the two-dimensional unsteady stagnation flow of an electrically conducting fluid, over shrinking surface in the presence of magnetic field. Under some special conditions, the problem will reduce the results obtained by previous researchers. The effects of different parameters such as the unsteadiness parameter, the velocity parameter, the magnetic parameter, the Prandtl number and the Eckert number are studied in detail. The velocity as well as thermal boundary layer thickness decreases with the increasing values of the unsteadiness parameter, the velocity parameter, the magnetic parameter, the Prandtl number and the Eckert number whereas in the velocity reverse phenomenon occurs for the magnetic parameter. From the results it can be concluded that skin friction and Nusselt number vary according to the velocity and thermal boundary layers thickness respectively with different parameters.

\section{References}

[1] Sakiadis, B.C. (1961) Boundary-Layer Behaviour on Continuous Solid Surfaces: I. Boundary-Layer Equations for Two Dimensional and Axisymmetric Flow. Journal of American Institute of Chemical Engineers (AIChE), 7, 26-28. http://dx.doi.org/10.1002/aic.690070108

[2] Crane, L.J. (1970) Flow past a Stretching Plate. Zeitschrift für Angewandte Mathematik und Physik, 21, 645-647. http://dx.doi.org/10.1007/BF01587695

[3] Gupta, P.S. and Gupta, A.S. (1977) Heat and Mass Transfer on a Stretching Sheet with Suction or Blowing. The Canadian Journal of Chemical Engineering, 55, 744-746. http://dx.doi.org/10.1002/cjce.5450550619

[4] Vleggaar, J. (1977) Laminar Boundary-Layer Behaviour on Continuous, Accelerating Surfaces. Chemical Engineering Science, 32, 1517-1525. http://dx.doi.org/10.1016/0009-2509(77)80249-2

[5] Soundalgekar, V.M. and Ramana Murty, T.V. (1980) Heat Transfer in Flow past a Continuous Moving Plate with Variable Temperature. Warme-und Stoffubertragung, 14, 91-93. http://dx.doi.org/10.1007/BF01806474

[6] Grubka, L.J. and Bobba, K.M. (1985) Heat Transfer Characteristics of a Continuous, Stretching Surface with Variable Temperature. Journal of Heat Transfer, 107, 248-250. http://dx.doi.org/10.1115/1.3247387

[7] Magyari, E. and Keller, B. (1999) Heat and Mass Transfer in the Boundary Layers on an Exponentially Stretching 
Continuous Surface. Journal of Physics D: Applied Physics, 32, 577-585. http://dx.doi.org/10.1088/0022-3727/32/5/012

[8] Elbashbeshy, E.M.A. and Bazid, M.A.A. (2003) Heat Transfer over an Unsteady Stretching Surface with Internal Heat Generation. Applied Mathematics and Computation, 138, 239-245. http://dx.doi.org/10.1016/S0096-3003(02)00106-6

[9] Jat, R.N. and Chaudhary, S. (2008) Magnetohydrodynamic Boundary Layer Flow near the Stagnation Point of a Stretching Sheet. Il Nuovo Cimento, 123B, 555-566.

[10] Jat, R.N. and Chaudhary, S. (2009) Unsteady Magnetohydrodynamic Boundary Layer Flow over a Stretching Surface with Viscous Dissipation and Joule Heating. Il Nuovo Cimento, 124B, 53-59.

[11] Jat, R.N. and Chaudhary, S. (2010) Radiation Effects on the MHD Flow near the Stagnation Point of a Stretching Sheet. Zeitschrift für Angewandte Mathematik und Physik, 61, 1151-1154. http://dx.doi.org/10.1007/s00033-010-0072-5

[12] Bachok, N., Ishak, A. and Nazar, R. (2011) Flow and Heat Transfer over an Unsteady Stretching Sheet in a Micropolar Fluid. Meccanica, 46, 935-942. http://dx.doi.org/10.1007/s11012-010-9353-5

[13] Zheng, L., Wang, L. and Zhang, X. (2011) Analytic Solutions of Unsteady Boundary Flow and Heat Transfer on a Permeable Stretching Sheet with Non-Uniform Heat Source/Sink. Communications in Nonlinear Science and Numerical Simulation, 16, 731-740. http://dx.doi.org/10.1016/j.cnsns.2010.05.022

[14] Mahapatra, T.R. and Nandy, S.K. (2011) Unsteady Stagnation-Point Flow and Heat Transfer over an Unsteady Shrinking Sheet. International Journal of Applied Math and Mechanics, 7, 11-26.

[15] Mahapatra, T.R. and Nandy, S.K. (2013) Slip Effects on Unsteady Stagnation-Point Flow and Heat Transfer over a Shrinking Sheet. Meccanica, 48, 1599-1606. http://dx.doi.org/10.1007/s11012-012-9688-1

[16] Aly, E.H. and Vajravelu, K. (2014) Exact and Numerical Solutions of MHD Nano Boundary Layer Flows over Stretching Surfaces in a Porous Medium. Applied Mathematics and Computation, 232, 191-204. http://dx.doi.org/10.1016/j.amc.2013.12.147

[17] Chaudhary, S. and Kumar, P. (2014) MHD Forced Convection Boundary Layer Flow with a Flat Plate and Porous Substrate. Meccanica, 49, 69-77. http://dx.doi.org/10.1007/s11012-013-9773-0

[18] Nandy, S.K., Sidui, S. and Mahapatra, T.R. (2014) Unsteady MHD Boundary Layer Flow and Heat Transfer of Nanofluid over a Permeable Shrinking Sheet in the Presence of Thermal Radiation. Alexandria Engineering Journal, 53, 929-937. http://dx.doi.org/10.1016/j.aej.2014.09.001

[19] Rosca, N.C. and Pop, I. (2015) Unsteady Boundary Layer Flow over a Permeable Curved Stretching/Shrinking Surface. European Journal of Mechanics—B/Fluids, 51, 61-67. http://dx.doi.org/10.1016/j.euromechflu.2015.01.001 